\title{
Cropping Patterns in the South East Coastal Region of Bangladesh
}

\author{
S. M. SHAHIDULlah ${ }^{1 *}$, M. S. A. TALUKDER ${ }^{1}$, M. S. KABIR $^{1}$, A. H. KHAN $^{2}$ AND \\ NUR-E-ELAHI ${ }^{2}$ \\ ${ }^{1}$ Bangladesh Rice Research Institute Regional Station, Sonagazi, Feni, Bangladesh \\ ${ }^{2}$ RFS Division, Bangladesh Rice Research Institute, Gazipur, Bangladesh
}

Received 08 May 2005; received in revised form 16 August 2005; accepted 22 June 2006

\begin{abstract}
The study was conducted in greater Noakhali district to investigate the major cropping patterns during 2000-2001. Information was collected through a structured interview schedule. A total of 18 major cropping patterns were identified. Most dominant cropping pattern, single T. Aman alone occupied 35\% land of net cropped area. The next three, Boro-Fallow-T. Aman, Fallow-B.Aus-T. Aman and single Boro represents 14, 11 and $11 \%$, respectively of the net cropped area. A sharp variation was observed in cropping patterns among the different upazillas. Crop land of Noakhali, Companiganj, and Ramgati is mainly occupied by single T. Aman cropping pattern. Lion share of net cropped area in Feni, Chhagalnaiya, Parshuram and Raipur is covered by Boro-Fallow-T. Aman pattern. Begumganj and Chatkhil are an exception. More than $80 \%$ of the cropped area is in these two upazillas is cahracterized by single Boro cropping pattern. The average cropping intensity of the greater Noakhali district was 163\%. The highest cropping intensity was $194 \%$ in Ramganj and the lowest $115 \%$ was in Begumganj. The highest adoption rate of modern rice varieties was found in Boro-Fallow-T. Aman cropping pattern in all upazillas. The farmers need improved varieties of Aus, T. Aman and minor Rabi crops purposively suitable for coastal area. Researches in these fields should get priority. Single Boro area, especially of Begumganj and Chatkhil is the most potential area for fish culture after the harvest of Boro rice.
\end{abstract}

Key words: Cropping patterns, cropping intensity, coastal area.

\section{INTRODUCTION}

A cropping pattern is the yearly sequence, temporal and partial arrangement of crops in a given land area. It is dependent on physical, historical, social, institutional and economic factors as well as government policies (Agrawal and Kassam, 1976). The cropping pattern and the changes therein depend on a large number of factors like climate, soil type, rainfall, agricultural technology, availability of irrigation facilities and other inputs, marketing and transport facilities and growth of agro-industries (Neena, 1998; Gadge, 2003). The south east coastal region holds an environment different from other parts of Bangladesh. About 78 thousand hectares of land is affected by salinity at different levels. The crop production is restricted due to salinity during dry season, a peculiar environmental and hydrological situation prevails in the region. It is the most serious threat to the coastal agriculture. Determinants that influence the dynamics of salinity which, in tern determine the type of cropping patterns to be followed in the saline area are: rainfall, temperature,

\footnotetext{
*Corresponding author: SSO, BRRI Regional Station, Sonagazi, Feni.

(C) 2006, School of Agriculture and Rural Development, Bangladesh Open University. All rights reserved.
} 
topography, crops and their varieties, and various socio-economic factors. The cropping intensity is much lower than those of non-saline areas of the country. Sweet water availability during dry season is very limited in the coastal area.

The yields of cereal crops are tending to stagnation, especially in favourable environments. Moreover, cultivable land area is decreasing day by day in the country. In this context, there is no other alternative but to address less favourable and unfavourable environments. To increase the system productivity of the total environment it needs to bring diversity in enterprises for better utilization of limited resources. A detail information on land situation and cropping systems is a prerequisite for a fruitful development programme. Upazilla level office of the Department of Agricultural Extension (DAE) maintains a statistics on individual crop, which has some limitation for getting a real picture of existing cropping patterns and land utilization. The present study was designed with the following objectives:

1. Build up a database on major existing cropping patterns in the south east coastal region of Bangladesh,

2. Know the status of modern rice varieties in different patterns and seasons and

3. Identify the constraints and explore the scope of better utilization of resources in the area.

\section{MATERIALS AND METHODS}

The study was conducted in greater Noakhali district during 2000-2001. The study area included all the fifteen upazillas, six in Noakhali, five in Feni and four in Laxmipur district. It holds an area of 6.17 lac hectares that shares $4.17 \%$ of the whole Bangladesh (BBS, 2001). It consists of 174 unions, the smallest administrative units. An interview schedule was developed by the multidisciplinary experts of the Rice Farming Systems Division of Bangladesh Rice Research Institute. Necessary modification was done after the field test of the interview schedule. Data were collected in different stages, viz. (i) Focus group discussion at union level, (ii) Verification and cross checking by another focus group, (iii) Finally the data were validated in the weekly discussion meeting of the DAE officers and Block Supervisors (BS) in the upazilla. Each focus discussion group (FDG) consists of 6-8 key informants. All the key informants were selected with the help of BS. In the interview schedule wheat, mustard and potato were considered as major non-rice crops in winter. All other crops including winter vegetables were grouped as Rabi crops. Crop diversity index (CDI) was calculated by using the following equation described by Kshirsagar (1997).

$$
\begin{aligned}
& C D I_{i}=1-\sum_{j=1}^{n}\left(\frac{a_{i j}}{A_{i}}\right)^{2} \\
& \text { Where, } C^{C D l_{i}}=\text { crop diversity index } \\
& a_{i j}=\text { area planted to the } j \text { th crop in the ith location } \\
& A_{i}=\text { total area planted under all crops. }
\end{aligned}
$$

The index is zero for a land area growing only one crop and approaches unity as the level of diversity increase. Yield was calculated as an average over ten crop cut results in each upazilla. Compilation and processing of collected data were done in Micro Soft Excel programme. Descriptive statistics were used to facilitate the presentation of the findings.

\section{RESULTS AND DISCUSSION}

\section{Area coverage of major cropping patterns}

Greater Noakhali district possesses 3.66 lac hectares of net cropped area. A total of 18 major cropping patterns were identified which covered about $93 \%$ of the net cropped area. Out of eighteen, only a single cropping pattern of single T. Aman occupied 1.28 lac hectare which holds $35 \%$ area. The three followers are Boro - Fallow - T. Aman, Fallow - B. Aus - T. Aman and Boro Fallow - Fallow. These top four represents more than $70 \%$ of the cultivated land (Table 1). Nur-EElahi et al. (1999) identified 34 cropping patterns all over the country. Among those, Boro-FallowT. Aman, single T. Aman and single Boro were most dominant which covered 22, 13 and 10\% area, respectively of net cropped area. That study was confined up to district level. 
Table 1. Area under major cropping patterns in greater Noakhali district, 2000- 2001

\begin{tabular}{lrr}
\hline Cropping pattern & Area coverage (ha) & \% to net cropped area \\
\hline \hline 01. Fallow - Fallow - T. Aman & 128,200 & 34.99 \\
02. Boro - Fallow - T. Aman & 50,650 & 13.82 \\
03. Fallow - B.Aus - T. Aman & 42,000 & 11.46 \\
04. Boro -Fallow - Fallow & 40,000 & 10.92 \\
05. Rabi - Aus - T. Aman & 25,100 & 6.85 \\
06. Rabi - Fallow - T. Aman & 20,200 & 5.51 \\
07. Groundnut - Aus - T. Aman & 13,000 & 3.55 \\
08. Fallow - T.Aus - T. Aman & 9,900 & 2.70 \\
09. Rabi - Vegetables & 4,000 & 1.09 \\
10. Boro -DW Aman & 1,500 & 0.41 \\
11. Rabi - B.Aus + B.Aman & 1,160 & 0.32 \\
12. Wheat - Fallow - T. Aman & 915 & 0.25 \\
13. Fallow - B.Aus + B.Aman & 900 & 0.25 \\
14. Potato - Fallow - T. Aman & 780 & 0.21 \\
15. Mustard - Boro - T. Aman & 750 & 0.21 \\
16. Mustard - Fallow - T. Aman & 310 & 0.09 \\
17. Wheat - T.Aus - T. Aman & 300 & 0.08 \\
18. Boro - Aus - Fallow & 200 & 0.05 \\
Others & 26,535 & 7.24 \\
\hline Total (Greater Noakhali) & $3,66,400$ & 100.00 \\
\hline
\end{tabular}

Another important feature of the region is that eight patterns out of 18 are composed of absolute rice crops. These are the above mentioned top four along with Fallow-T.Aus-T. Aman, Boro-DW Aman, Fallow-B.Aus+B.Aman and Boro-Aus-Fallow. About $75 \%$ of the crop land belongs to these eight patterns of single or double rices. A very negligible portion, less than $1 \%$ of net cropped area is occupied by five minor cropping patterns consisting wheat, mustard and potato. These crops do not perform well in the coastal region due to shorter (30-40 days) winter period compared to that of north-west region ( $3-4$ months). The turn around time after T. Aman harvest in the coastal saline environment is very short to catch Rabi crop (Karim, 1990). Moreover, rapid tillage operation in many cases is not possible because of late November shower.

In the Rabi season, about $50 \%$ of the cropped area remains fallow under single T. Aman and Fallow - B. Aus/T. Aus - T. Aman cropping patterns. In this period a vast portion of this fallow area is used as an unplanned grazing land of buffaloes and sheep. Drought resistant and saline tolerant crops like barley and triticale could be tried to grow for grain as well as fodder. Grass pea is grown as a relay crop with $\mathrm{T}$. Aman to a limited scale. It also could be expanded in unexploited areas.

\section{Land utilization in different upazillas}

A wide variation was observed in cropping patterns among the different upazillas. Seven upazillas viz. Noakhali, Companiganj, Senbagh, Hatiya, Dagonbhuiyan, Ramgati and Laxmipur are dominated by single T. Aman cropping pattern. Only this one covers about $60 \%$ land of net cropped area in Noakhali, Companiganj, and Ramgati (Table 2).

The existence of Boro-Fallow-T. Aman cropping pattern is almost common in every upazillas but dominant only in Feni, Chhagalnaiya, Parshuram and Raipur. About two-thirds cultivated land of these four upazillas are allocated for the pattern.

Fallow-B.Aus-T. Aman is the most important cropping pattern in Sonagazi and it represents about half of the cultivated area. It is important also in Senbagh, Hatiya and Ramganj and negligible in other parts of the region. In the Aus crop establishment, broadcasting and dibbling methods are practised simultaneously. In the dibbling method, seeds are put in a deeper hole to ensure the moisture and for the escape of germinating seeds from saline soil crust.

Single Boro cropping pattern is available in several upazillas. Begumganj and Chatkhil are an extreme exception for single Boro for which more than $80 \%$ of the area is allocated. Cultivation 
system of these two upazillas is characterized by a unique hydro-ecological situation completely different from any other part of the country. It is a vast field of medium high land and medium lowland with a very shallow water table. For a long period of the year its stagnant water holds a thick cover of aquatic weeds that helps organic matter deposition in the soil. Crop is almost dependent on surface water from ponds and ditches and sometimes canals.

Table 2. Area covered by dominant cropping patterns in different upazillas of greater Noakhali district, 2000- 2001

\begin{tabular}{|c|c|c|c|c|}
\hline \multirow{2}{*}{ Upazilla } & \multirow{2}{*}{$\begin{array}{l}\text { Net cropped area } \\
\text { (NCA) in ha }\end{array}$} & \multicolumn{3}{|c|}{ Status of dominant cropping patterns } \\
\hline & & Cropping patterns & Area (ha) & $\%$ of NCA \\
\hline 01. Noakhali & 67,000 & F- F- T. Aman & 40,000 & 60 \\
\hline 02. Companiganj & 22,000 & F- F- T. Aman & 12,500 & 57 \\
\hline 03. Begumganj & 26,500 & Boro- F- F & 22,000 & 83 \\
\hline 04. Chatkhil & 8,700 & Boro- F- F & 7,000 & 80 \\
\hline \multirow[t]{4}{*}{ 05. Senbagh } & 12,500 & F- F- T. Aman & 4,000 & 32 \\
\hline & & Boro- F- F & 2,000 & 16 \\
\hline & & F- B.Aus- T. Aman & 2,000 & 16 \\
\hline & & Boro- F- T. Aman & 2,000 & 16 \\
\hline \multirow[t]{3}{*}{ 06. Hatiya } & 55,000 & F- F- T. Aman & 15,000 & 27 \\
\hline & & F- B.Aus- T. Aman & 10,000 & 18 \\
\hline & & G.nut-Aus-T. Aman & 8,000 & 15 \\
\hline 07. Feni & 16,500 & Boro- F- T. Aman & 10,000 & 61 \\
\hline 08. Parshuram & 12,700 & Boro- F- T. Aman & 8,300 & 65 \\
\hline 09. Chhagalnaiya & 10,000 & Boro- F- T. Aman & 7,000 & 70 \\
\hline \multirow[t]{3}{*}{ 10. Dagonbhuiyan } & 10,500 & F- F- T. Aman & 3,500 & 33 \\
\hline & & Boro- F- T. Aman & 2,400 & 23 \\
\hline & & F- T.Aus- T.Aman & 2,000 & 19 \\
\hline \multirow[t]{2}{*}{ 11.Sonagazi } & 21,000 & F- B.Aus- T. Aman & 10,000 & 48 \\
\hline & & F- F- T. Aman & 5,800 & 28 \\
\hline 12. Ramgati & 48,000 & F- F- T. Aman & 27,000 & 56 \\
\hline 13. Raipur & 11,500 & Boro- F- T. Aman & 6,500 & 57 \\
\hline \multirow[t]{2}{*}{ 14. Laxmipur } & 36,000 & F- F- T. Aman & 12,000 & 33 \\
\hline & & Boro- F- T. Aman & 10,000 & 28 \\
\hline \multirow[t]{4}{*}{ 15. Ramganj } & 8,500 & Boro- F- T. Aman & 2,000 & 24 \\
\hline & & Boro- F- F & 1,000 & 12 \\
\hline & & F- B.Aus- T. Aman & 1,000 & 12 \\
\hline & & Boro- DW Aman & 1,000 & 12 \\
\hline
\end{tabular}

Groundnut-Aus-T. Aman is a different cropping pattern exists only in Hatiya, which covers $15 \%$ area. The newly formed light soil of the upazilla is very suitable for the groundnut cultivation. Replacement of local varieties by high yielding varieties of groundnut might be a tool for the increase of productivity. Boro-DW Aman is a cropping pattern in the bank of extinction. A considerable land area is steel now under this cultivation in Ramganj.

Number of cropping patterns is a gross indicator of crop diversity. The highest number of cropping patterns identified was 12 in Laxmipur and the lowest was six in Chatkhil. Calculated crop diversity indeces (CDI) for the upazillas are also presented in the Table 3. Over all crop diversity index in the 
greater Noakhali was 0.70 . The highest CDI was found 0.76 in Hatiya and Ramganj and the lowest 0.41 in Begumganj. The average cropping intensity of the greater Noakhali district was $163 \%$. The highest cropping intensity was $194 \%$ in Ramganj and the lowest $115 \%$ was in Begumganj.

Table 3. Crop diversity and cropping intensity $(\mathrm{Cl})$ in different upazillas of greater Noakhali district, 2000- 2001

\begin{tabular}{|c|c|c|c|c|c|c|}
\hline \multirow[b]{2}{*}{ Upazilla } & \multirow{2}{*}{$\begin{array}{l}\text { Number of } \\
\text { identified } \\
\text { patterns } \\
\end{array}$} & \multirow[b]{2}{*}{ CDI } & \multicolumn{3}{|c|}{ Cropped area (ha) } & \multirow[b]{2}{*}{$\mathrm{Cl}(\%)$} \\
\hline & & & Single & Double & Triple & \\
\hline 01. Noakhali & 10 & 0.59 & 50,000 & 11,000 & 6,000 & 134 \\
\hline 02. Companiganj & 10 & 0.66 & 12,500 & 6,500 & 3,000 & 157 \\
\hline 03. Begumganj & 7 & 0.41 & 23,000 & 3,000 & 500 & 115 \\
\hline 04. Chatkhil & 6 & 0.48 & 7,000 & 1,200 & 500 & 125 \\
\hline 05. Senbagh & 10 & 0.72 & 6,000 & 6,000 & 500 & 156 \\
\hline 06. Hatiya & 7 & 0.76 & 20,000 & 20,000 & 15,000 & 191 \\
\hline 07. Feni & 8 & 0.69 & 3,000 & 12,500 & 1,000 & 188 \\
\hline 08. Parshuram & 8 & 0.67 & 3,000 & 9,200 & 500 & 180 \\
\hline 09. Chhagalnaiya & 8 & 0.68 & 1,000 & 8,500 & 500 & 195 \\
\hline 10. Dagonbhuiyan & 9 & 0.69 & 3,500 & 6,000 & 1,000 & 176 \\
\hline 11.Sonagazi & 9 & 0.66 & 6,000 & 14,000 & 1,000 & 176 \\
\hline 12. Ramgati & 10 & 0.74 & 28,000 & 12,000 & 8,000 & 158 \\
\hline 13. Raipur & 7 & 0.73 & 2,000 & 8,500 & 1,000 & 191 \\
\hline 14. Laxmipur & 12 & 0.71 & 14,000 & 18,000 & 4,000 & 172 \\
\hline 15. Ramganj & 11 & 0.76 & 2,000 & 5,000 & 1,500 & 194 \\
\hline Greater Noakhali & 18 & 0.70 & 181,000 & 141,400 & 44,000 & 163 \\
\hline
\end{tabular}

The interrelationship between cropping intensity, crop diversity index and the number of cropping patterns was calculated in terms of correlation coefficient. From this analysis, it is observed that $\mathrm{Cl}$ and $\mathrm{CDI}$ were positively correlated with a coefficient value 0.84 . A linear relationship between $\mathrm{Cl}$ and CDI was with $?=0.70$ (Fig. 1). The number of cropping patterns showed a negligible relationship $\left(r^{2}=0.012\right)$ with $\mathrm{Cl}$ and a poor relationship $\left(r^{2}=0.20\right)$ with CDI.

\section{Adoption level and yield of MV rices under different cropping patterns}

Adoption of modern rice varieties is highly dependent on land situation, irrigation facilities and other inputs. It may show a great fluctuation in different locations under the same cropping pattern and in different cropping patterns of similar location. In the study area, adoption rate of modern Boro is almost $100 \%$ in Boro-Fallow-T. Aman cropping pattern. But in single Boro it ranges from 90 to $99 \%$ in different locations (Table 4). Some pocket area under the threat of flush flood in bottom land is out of modern Boro cultivation.

In T. Aman season modern varieties cover $18-100 \%$ area of Fallow-Fallow-T. Aman, BoroFallow-T. Aman and Fallow-Aus-T. Aman cropping patterns. This wide variation is mainly due to land type, soil salinity and lack of irrigation facilities. Medium high land-II is not usually suitable for modern Aman transplanting. In addition, some local varieties are specially preferred for different/specific purposes. Modern rice adoption rate in Aus season is $18-100 \%$ over the greater Noakhali district. Irrespective of season and cropping pattern, adoption rate is the highest in Dagonbhuiyan and the lowest in Hatiya.

Binnatoa is a popular local Aus and Rajasail and Kajalsail are two dominant local varieties of T. Aman. Basically they are not characterized by high salt tolerance. But these land races have got stability/adaptation by cultivation over yeras. Among the modern Aus varieties, BRRIdhan27 is getting popularity because of its taller plant type and increasing adaptation. Modern T. Aman varieties like BR22, BR23, BRRIdhan40 and BRRIdhan41 have slight tolerance to salinity. These varieties could be expanded tremendously. Efforts should be given on continuous research trials 
with a large number of genotypes. Selected genotypes from the regional trials could be expected to perform well over time.

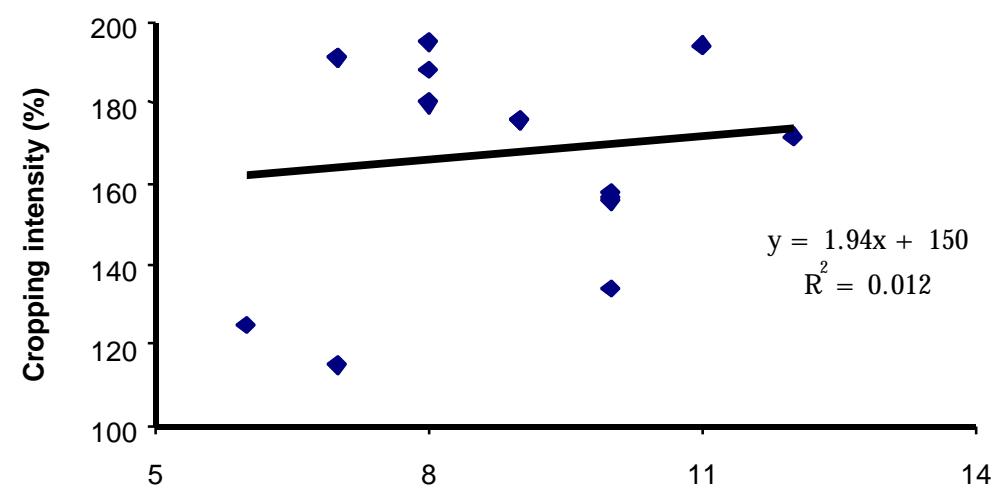

No. of cropping patterns

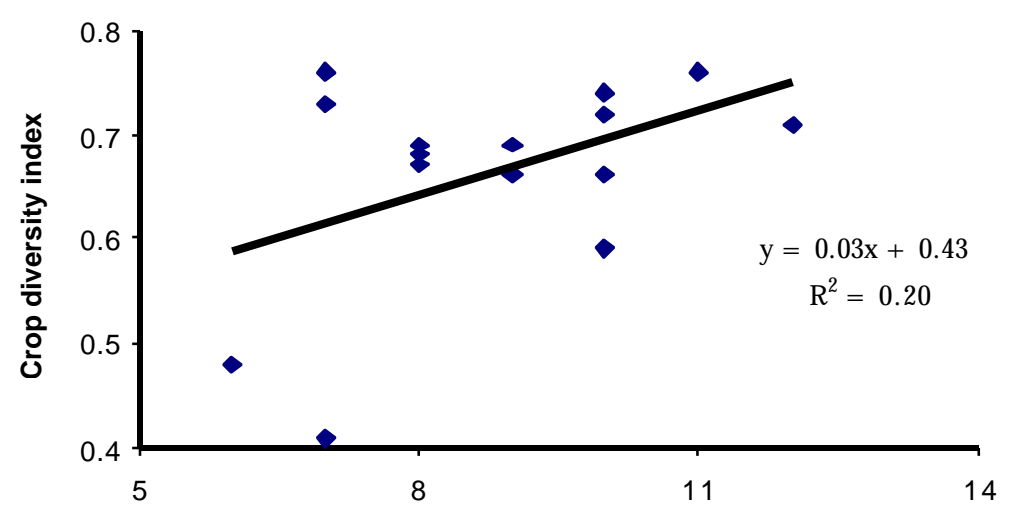

No. of cropping patterns

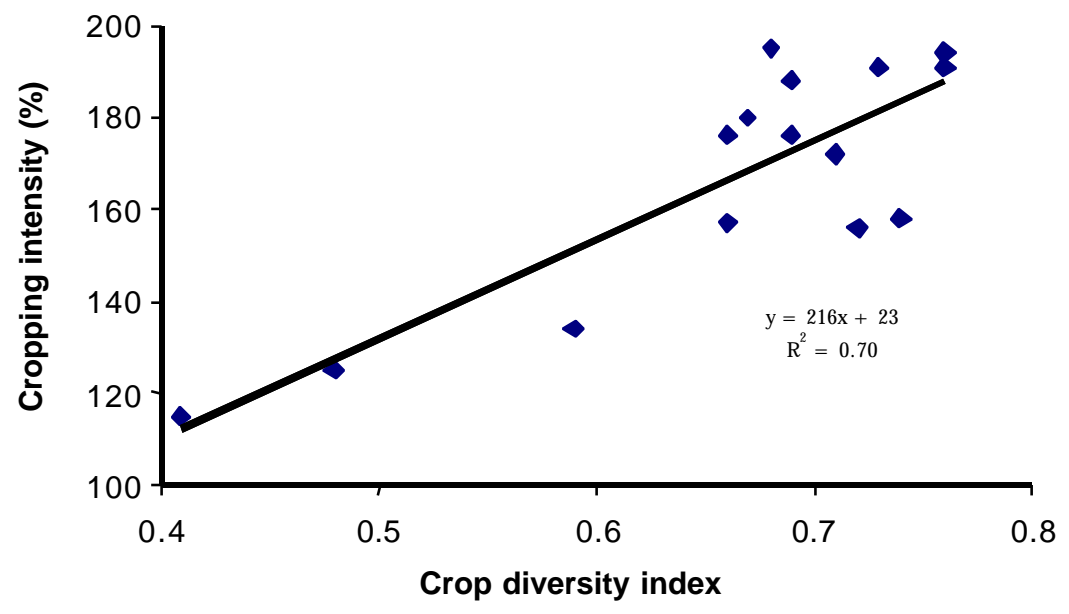

Fig. 1. Relationship between different pairs of parameters 
Table 4. Adoption of modern varieties of rices (MV rices) in different upazillas under dominant cropping patterns, 2000- 2001

\begin{tabular}{|c|c|c|c|c|c|c|}
\hline \multirow{2}{*}{ Upazilla } & \multirow{2}{*}{ Boro- F- F } & \multirow{2}{*}{ F- F- T. Aman } & \multicolumn{2}{|c|}{ Boro- F- T. Aman } & \multicolumn{2}{|c|}{ F-Aus-T. Aman } \\
\hline & & & Boro & T. Aman & Aus & T. Aman \\
\hline 01. Noakhali & 98 & 20 & "- & ב- & 30 & 20 \\
\hline 02. Companiganj & - & 20 & 100 & 25 & 50 & 25 \\
\hline 03. Begumganj & 95 & - & 100 & 25 & 50 & 25 \\
\hline 04. Chatkhil & 99 & - & - & - & 70 & 30 \\
\hline 05. Senbagh & 90 & 60 & 100 & 80 & 80 & 60 \\
\hline 06. Hatiya & - & 18 & - & - & 18 & 18 \\
\hline 07. Feni & - & 90 & 100 & 90 & 60 & 90 \\
\hline 08. Parshuram & - & 80 & 100 & 80 & 80 & 80 \\
\hline 09. Chhagalnaiya & - & 65 & 100 & 70 & 70 & 60 \\
\hline 10. Dagonbhuiyan & - & 100 & 100 & 75 & 50 & 75 \\
\hline 11.Sonagazi & - & 50 & 100 & 100 & 70 & 50 \\
\hline 12. Ramgati & - & 25 & 100 & 100 & 25 & 25 \\
\hline 13. Raipur & - & 70 & 98 & 80 & - & - \\
\hline 14. Laxmipur & 90 & 20 & 100 & 50 & 20 & 20 \\
\hline 15. Ramganj & 98 & - & 100 & 80 & 30 & 70 \\
\hline
\end{tabular}

Modern rice yield of single Boro is $4.5-5.2 \mathrm{t} / \mathrm{ha}$ (Table 5). The highest yield was recorded in Ramganj and Noakhali upazilla was the lowest in position. The yield of single T. Aman ranges from 3.2 to $4.2 \mathrm{t} /$ ha in different upazillas. Total rice yield of Boro-Fallow-T. Aman ranges from 7.0 to 8.5 $\mathrm{t} / \mathrm{ha}$ and that of Fallow-Aus-T. Aman is 5.5-7.2 t/ha. After overall consideration it could be said that the highest yields of modern varieties of rice were recorded in Ramganj/Parshuram and the lowest in Noakhali/Senbagh upazillas.

Table 5. Total grain yield ( $t$ ) of modern varieties of rice of different cropping patterns in the upazillas of greater Noakhali district, 2000- 2001

\begin{tabular}{lcccc}
\hline Upazilla & Boro- F- F & F- F- T. Aman & Boro- F- T. Aman & F-Aus-T. Aman \\
\hline \hline 01. Noakhali & 4.5 & 3.3 & - & 5.8 \\
02. Companiganj & - & 3.5 & 7.2 & 6.0 \\
03. Begumganj & 5.0 & - & 7.7 & 6.5 \\
04. Chatkhil & 5.0 & - & - & 6.0 \\
05. Senbagh & 4.8 & 3.5 & 7.0 & 5.5 \\
06. Hatiya & - & 4.2 & - & 7.0 \\
07. Feni & - & 4.0 & 8.0 & 6.5 \\
08. Parshuram & - & 4.2 & 8.5 & 7.2 \\
09. Chhagalnaiya & - & 4.0 & 8.4 & 6.5 \\
10. Dagonbhuiyan & - & 4.0 & 8.2 & 6.8 \\
11.Sonagazi & - & 4.0 & 8.0 & 7.0 \\
12. Ramgati & - & 3.5 & 8.3 & 5.8 \\
13. Raipur & - & 4.0 & 7.9 & - \\
14. Laxmipur & 5.0 & 3.2 & 7.4 & 6.0 \\
15. Ramganj & 5.2 & - & 8.5 & 7.0 \\
\hline
\end{tabular}

\section{Constraints to adoption of improved technologies}

A series of constraints were identified in the survey activities. Ten major of those were prioritized and presented in the Table 6 . According to the severity ranking 'unplanned polder/embankment construction' is the most serious one. It results the siltation in rivers and canals. In most of the cases, repair and maintenance of the constructions is not done properly. It aggravates the water stagnation situation in an additional scale. 'Poor soil in charland' and 'soil salinity' are the two least frequent constraints possess higher ranks. The most common and frequent constraint is the high price of agricultural inputs, but in the order of ranking it got least priority. 
Table 6. Constraints to adoption of improved technologies in crops and cropping patterns in greater Noakhali district

\begin{tabular}{lccc}
\hline \multirow{2}{*}{ Constraints } & $\begin{array}{c}\text { Ranking of } \\
\text { severity }\end{array}$ & Number & $\%$ \\
\cline { 3 - 4 } & & 83 & 48 \\
1. Unplanned polder/embankment & 2 & 64 & 37 \\
2. Poor soil of charland & 3 & 76 & 44 \\
3. Water stagnation & 4 & 65 & 37 \\
4. Soil salinity & 5 & 71 & 41 \\
5. Groundwater salinity & 6 & 111 & 64 \\
6. Absentee farmer & 7 & 119 & 68 \\
7. People's tendency of going abroad & 8 & 98 & 56 \\
8. Lack of knowledge & 9 & 150 & 86 \\
9. Lack of suitable crops and varieties & 10 & 160 & 92 \\
10. High price of agricultural inputs & & &
\end{tabular}

\section{CONCLUSION}

Non-rice Rabi crops hold a poor position in the agriculture of the south east coastal region. As a result crop diversification is restricted. Adoption of modern rice varieties in Kahrif season is very low in several upazillas. The farmers need improved varieties of Aus, T. Aman and minor Rabi crops purposively suitable for coastal area. Researches in these fields should get priority.

Drought resistant and saline tolerant crops like barley, triticale and other suitable pulse crops could be tried to grow for feed as well as food.

Rapid expansion programme of BRRIdhan27 in Aus Season and BR22, BR23, BRRIdhan40 and BRRIdhan41 in Aman season should continue. Regional trial for searching new genotypes should strengthen.

Single Boro area, a broad avenue, could be emphasized and addressed in different way. Begumganj and Chatkhil are the most potential area for rice-fish culture. After Boro harvest, successful rearing and catching of fishes is very possible in the boundary of frequently available natural barriers. Effort could be initiated in research for the development of packages of appropriate technologies.

\section{LITERATURE CITED}

Agrawal, D. J. and Kassam, A. H. 1976. The importance of multiple cropping in increasing world food supplies. A special publication No. 27, American Society of Agronomy, Madison, Wisconsin. pp. 2-3.

BBS.2001. Bangladesh Bureau of Statistics. Statistical year book of 2001, Ministry of Planning, Dhaka. p. 125.

Gadge, S. S. 2003. Influence of changes in cropping pattern on farmers' economic status. Indian J Ext Edu 39(1\&2), 99-101.

Karim, Z., Hussain, S. G. and Ahmed, M. 1990. Salinity problems and crop intensification in the coastal regions of Bangladesh. BARC Soils publication No. 33, Bangladesh Agricultural Research Council, Dhaka-1215. $63 \mathrm{pp}$.

Kshirsagar, K. G., Pandey, S. and Bellon, M. R. 1997. Farmers' perception, varietal characteristics and technology adoption: The case of rainfed village in eastern India. Discussion paper 5/97. Social Science Division, IRRI.

Neena, D. 1998. Interstate variation in cropping pattern in India. Indian J Regi Sci 30(2), 57-69.

Nur-E-Elahi., Khan, A. H., Siddique, M. R., Saha, A., Nasim, M., Mollah, M. I. U. and Shahidullah, S. M. 1999. Existing cropping patterns of Bangladesh, potential technologies and strategies for improving systems productivity. Proceedings of the workshop on modern rice cultivation in Bangladesh, held at Bangladesh Rice Research Institute, Gazipur 1701, 14-16 February 1999. pp.107-169. 